\title{
ESTO NO ES UNA NOTA NECROLÓGICA
}

\author{
JosÉ J. GÓMEZ ASENCIO \\ Universidad de Salamanca \\ Para Luis Santos y Julio Borrego, \\ condiscipulos y amigos \\ (o al revés)
}

No es una nota necrológica, en efecto. Es (o al menos eso deseo que sea) un apunte para un capítulo de [una] historia de la lingüística española.

Me piden los responsables de la Revista de Filología Española, por boca de su Secretaria, doña Pilar García Mouton, que escriba una nota sobre él, su persona y su obra. No me ponen restricciones ni de espacio, ni de tono, ni de estilo, ni de contenidos, ... Intuyo que, ocupe el que ocupe, escriba como escriba y diga lo que diga, mucho quedará en el tintero -o en bites desocupados del disco duro -; bastantes matices apreciativos de carácter delicado o sutil escaparán a mi inteligencia o a mi torpe sensibilidad; no poco se ocultará a mis pesquisas por los recovecos de la memoria propia y ajena: sólo la suya fue perfecta en grado cercano a la de Funes, el memorioso borgiano. Todos los que lo conocieron podrán, con seguridad, añadir algo que he eludido, omitido, olvidado, ocultado, descuidado, algo tal vez más importante, sea en perspectiva pública o de ámbito privado, que lo que yo pueda decir aquí. Corro, además, el peligro de otros riesgos: que esto acabe siendo un frío currículum, una aséptica lista de méritos, o aboque en un apasionado, cálido y - puesto que a nuestro personaje le cuadra mejor que a nadie el adjetivo- entrañable ditirambo. Y me enfrento, inseguro, a un desafio: encontrar un medio justo y acertado entre uno y otro extremos; hacerle justicia.

Redactar esa nota no resulta en absoluto tarea fácil (aunque sí grata: créanme) para quien pasó tantas horas y kilómetros a su lado, para quien tanto trabajó, vivió, vio y bebió, sintió y aprendió, comió o conoció, disfrutó o padeció junto a él.

RFE, LXXX, 2000, 3. $.^{\circ} .^{\circ}$, págs. $385-394$ 
Nació en la capital charra en uno de los últimos días de marzo del año 22. Le pusieron Antonio. Hijo de un tal Llorente, un curtidor de pieles en cuya tenería a orillas del río - al pie mismo del puente romano tan familiar a Lázaro de Tormes- aprendió a escribir a máquina, habilidad por cierto que nunca puso, que se sepa, al servicio de la lingüística española: la tecnología más avanzada con la que lo vimos escribir era un bolígrafo "bic cristal". Nieto de don Luis Maldonado, catedrático de Derecho en el estudio salmantino, rector de la Universidad de Salamanca, íntimo de don Miguel de Unamuno, presunto - pero seguro- autor de unas críticas coplas anónimas ', las Querellas del ciego de Robliza, por cuya persona, erudición, comportamiento y saberes siempre manifestó auténtica devoción, y cuya casa de la calle Toro recordaba a menudo con nostalgia. Descendiente remoto de Francisco Maldonado, comunero rebelde contra Carlos I, uno de los ajusticiados en Villalar el 24 de abril de 1521 ("un carca, Pepe, un carca, un involucionista, por mucho que ahora sea poco menos que elevado a los altares por los progres regionalistas castellano-leoneses"; comunicación oral, circa 1978). Nunca le oí alardear de estos hechos, ni de cualquier otra cualidad que lo adornara: humilde. Hablamos de Antonio Llorente Maldonado de Guevara, de Llorente.

De muchacho estudió bachillerato en el colegio de Calatrava, a la espalda misma del convento de los dominicos, casi pared con pared con San Esteban; allí destacó ya por sus habilidades para el fútbol, por su rapidez e inteligencia en el juego, tales que a punto estuvo de ser fichado como profesional para el Real Madrid de entonces, algo a lo que (por fortuna para la lingüística española, para la Universidad de Salamanca y, modesta y privadamente, para el que esto escribe) su padre se opuso rotundamente. Terminó, pues, Filosofía y Letras. ¿En qué especialidad? En cualquiera de ellas: todas debieron de cuadrarle entonces y en todas fue un experto después: ¿Lingüista? Sí. ¿Gramático? Sí. Pero también dialectólogo, romanista, latinista o hispanista en general. Y geógrafo, historiador, arqueólogo, antropólogo, etnógrafo, conocedor profundo de Salamanca y lo salmantino. Como - saliendo de esos terrenos de las letras - labrador, experto en ganado o en nutrición, enólogo, gastrónomo, meteorólogo consumado, zoólogo, botánico, astrónomo, anatomista, ... qué sé yo qué más.

\footnotetext{
${ }^{1}$ Véanse: "Las Querellas del ciego de Robliza, de Luis Maldonado, I (Noticias sobre la génesis, difusión y estimación del poema)", en Estudios sobre Literatura y Arte dedicados al profesor Emilio Orozco Díaz, Granada, 1979, págs. 311-322. "Las Querellas del ciego de Robliza, de Luis Maldonado, II: Estructura externa y contenido del poema", en Estudios Románicos dedicados al profesor Andrés Soria Ortega, Granada, 1985, págs. 317-325. Y "Las Querellas del ciego de Robliza, de Luis Maldonado, III: carácter social del poema”, en Studia Litteraria atque Linguistica N. Marin. J. Fernández-Sevilla et P. González Oblata, Granada, 1988 , págs. $55-75$.
} 
Era una especie de "Espasa" viva, ambulante, versátil, simultánea y -perdóneme, don Antonio- on line, repleta de links, de remisiones y enlaces internos; un "Larousse" al que todos hemos acudido para despejar dudas de toda índole. Nunca he alcanzado a formular con precisión en cuál de esas actividades, profesiones o especialidades era más entendido: sé con cuáles de ellas se ganaba su salario regular y sus extras, su sustento y el de su familia; intuyo con cuáles de ellas se lo pasaba mejor; pero jamás me ha sido posible determinar de cuál de ellas sabía más. Estuvo dotado de una curiosidad intelectual inagotable e insaciable que le duró tanto como su propia vida. $\mathrm{Na}-$ die jamás ha conseguido enterarse de cómo, cuándo, dónde o de quién aprendió tantas cosas como sabía, sabiduría de la que nunca supo presumir: humilde otra vez, y sabio. Su familiaridad y naturalidad con los datos, con todos los datos imaginables de cualquier disciplina o ámbito imaginables, eran tales que se podía llegar a pensar que no los había adquirido entre otras cosas porque no habría tenido tiempo para tantos - y le eran, de consiguiente, infusos. Su capacidad para concatenarlos, su fino criterio para evaluarlos, su desparpajo para presentarlos, su soltura y desenfado - lejanos de encorsetamientos, protocolos y vanas petulancias - en el manejo de la información causaban admiración. A menudo daba la impresión de que él no indagaba en busca del conocimiento, sino al contrario: los datos, las relaciones entre los fenómenos... lo buscaban a él, se le imponían por sí solos, se le revelaban en exclusiva y con facilidad, gratuitamente. Nada más falso. Su sencillez hacía que muchos creyeran tal: sencillo y modesto.

En sus años mozos (entre 1943 y 1947) enseñó en la misma Facultad salmantina de Filosofía y Letras en la que se había formado "Geografía general y de España" (asignatura, por cierto, en la que si la memoria no me traiciona suspendió - él, que tan dado era a aprobarnos a todos o, a lo menos, a los más posibles: benevolente- a Carmen Martín Gaite: "algo inexplicable, Pepe, no lo puedo entender"), "Historia del Arte", "Arqueología, Epigrafía y Numismática" o "Historia de la Literatura española". En esos mismos años y casi casi hasta su muerte dio clases de otras muchas materias, estas sí estrictamente filológicas o lingüísticas, pertenecientes a planes de estudios reglados: "Gramática general", "Crítica literaria", "Filología románica", "Filología galaico-portuguesa", "Fonética experimental", "Lingüística románica", "Lingüística general y Estilística", "Gramática general y española", "Introducción a la toponimia", "Semántica", "Lengua española", "Morfosintaxis del español", "Dialectología hispánica". No se tiene noticia de alumno descontento o quejoso: profesor excelente.

Tampoco hemos oído críticas y sí en cambio encendidos y desinteresados elogios de aquellos que pasaron por las aulas mientras él explicaba alguno de los innumerables cursos monográficos de doctorado que le tocó 
impartir (palabra ésta que él no habría usado, creo): he contado no menos de 17 diferentes en Granada y otros 15 en Salamanca. Versaron sobre temas dispares que van desde "Métrica general y versificación española" o "El problema de los géneros literarios" hasta "Filosofia del lenguaje" o "Lingǘstica sintética o externa", con claro predominio de los dedicados a toponimia, claramente una de sus inclinaciones, tal vez la mayor de sus debilidades científicas, la que diese secreta cohesión a saberes sueltos y a tanto conocimiento acumulado en un solo ser humano, la que integrara -núcleo centrípeto- informaciones y curiosidades aparentemente dispersas y dispares: amante de todos los nombres propios, de lugar, persona y cosa.

Sobre nombres de lugar publicó más de una docena de trabajos hoy imprescindibles que reclaman a gritos una reedición inminente; en ese anhelado volumen podrían incluirse además trabajos inéditos, manuscritos donde se contienen conferencias, cursos de doctorado, apuntes de clase o notas de uso y reflexión personales. Resulta inexcusable citar aquí su Toponimia $e$ historia (Granada, 1969; 2. ${ }^{\mathrm{a}}$ ed. en 1972), su Los topónimos españoles y su significado (Salamanca, 1986) o la sustanciosa e instructiva sarta de artículos dedicados a la toponimia salmantina ${ }^{2}$, de aplicación y validez mucho más generales de lo que su localista título sugiere.

Sobre nombres de lugar y de persona le consultaron curiosos en general, indoeuropeístas, arabistas, geógrafos, vascólogos, medievalistas, historiadores de la Antigüedad, de la Iglesia o del español, geomorfólogos, expertos en lenguas ibéricas o celtas, ... Sobre nombres de persona le pidieron ayuda -y certificación escrita que ellos insistían en pagar y él se negaba en redondo a cobrar- todos aquellos salmantinos que pretendian po-

2 Tengo constancia de los siguientes (obsérvese cómo cuando se escribió el primero el autor ya parecía tener una idea bien clara del conjunto; cómo todos ellos no parecen sino capítulos sueltos de un texto único muy probablemente concebido de antemano; o cómo los títulos son deliberadamente precisos aun a fuer de largos): "Esquema toponímico de la provincia de Salamanca: topónimos prerromanos", en STRENAE. Estudios de Filologia e Historia dedicados al profesor Manuel García Blanco, Salamanca, 1962, págs. 309-332. "La toponomia árabe, mozárabe y morisca de la provincia de Salamanca", en Miscelánea de Estudios árabes $y$ hebraicos, XII-XIII, 1963-1964, Granada, 1966, págs. 89-112. "Esquema toponímico de la provincia de Salamanca: topónimos latinos de romanización, I (topónimos cuyo carácter de romanización es muy probable)", en Studia Hispanica in honorem $R$. Lapesa, II, Madrid, 1974, págs. 297-310. "Esquema toponímico de la provincia de Salamanca: topónimos latinos de romanización, II (topónimos probablemente relacionados con la romanización)", en Homenaje a D. Vicente García de Diego, en Revista de Dialectologia y Tradiciones Populares, XXXIII, Madrid, 1976, págs. 301-307. "Esquema toponímico de la provincia de Salamanca: topónimos latinos de romanización, III (topónimos de origen dudoso, con cierta probabilidad de remontarse a la romanización)", en Homenaje a Julio Caro Baroja, Madrid, 1978, págs. 698710. Ello sin contar el aparecido en el homenaje a Michelena: "Topónimos salmantinos y repobladores vasconavarros", en Symbolae Lvdovico Mitxelena Septuagenario oblatae, Victoriaco Vasconum, 1985, I, pars prior, págs. 721-734. 
ner a su hijo o hija uno que no aparecía en las listas de que disponían los funcionarios del registro civil: éstos remitían al interesado a una entelequia llamada "la Universidad", de donde aquél era reenviado a una persona concreta llamada don Antonio Llorente, "que es el que más sabe de esas cosas". Ésta ha sido dondequiera que haya estado o lo hayan conocido una de las frases más oídas en relación con su persona.

Llorente dirigió más de sesenta tesinas (sí, tesinas de las de antes); de ellas, unas veinte en Granada entre 1964 y 1973; el resto en Salamanca. Y no menos de veinticinco tesis doctorales; de ellas, unas ocho se leyeron en Granada entre 1972 y 1974. En todas ellas aconsejaba, orientaba, conducía, asesoraba, sugería pautas, pero nunca impuso su criterio: tolerante. Si durante el proceso de elaboración se suscitaba algún tipo de debate o disensión científicos entre director y autor, él era propenso a zanjarlo amablemente con un "tal vez tenga usted razón; no sé", con un "a lo mejor es como usted dice; no sé, no sé", o con un "déjelo como está, que así seguro que está bien". A mí por lo menos, el paso del tiempo me ha llevado a pensar que él sí sabía, que yo no tenía razón, que era como él decía y que hubiera sido mejor cambiarlo cuando no se cambió. Los ámbitos temáticos que más se repiten en esos trabajos de investigación - lo que no tiene nạda de extraño dadas las inclinaciones científicas del director-son la dialectología, la sociolingüística, la historia de las ideas lingüísticas, la toponimia, la gramática y la lexicología.

Y, así, creó escuela, o escuelas según se mire: una en Granada, de cuya universidad fue catedrático durante los 21 cursos académicos que corrieron entre 1950 y 1971, y otra en Salamanca, en donde enseñó sin parar desde 1971 hasta que le llegó la hora de la muerte. Entre los autores de aquellas tesinas y tesis que hoy se enorgullecen de ser discípulos suyos se cuentan (cito sólo a algunos de mis amigos cercanos y me permito incluir mi nombre tras el de dos que lo son de una manera muy especial) José Andrés de Molina Redondo, Antonio Narbona Jiménez, Juan Martínez Marín, Pedro Barros García, Juan de Dios Luque Durán, Juan Antonio Moya Corral, Julio Borrego Nieto, Luis Santos Río, José J. Gómez Asencio, César Real Ramos, Luis Cortés Rodríguez, Ignacio Coca Tamame, María Lourdes García Macho, María de las Nieves Sánchez González de Herrero, Eugenio de Bustos Gisbert, Juan Carlos González Ferrero, Eric Wagemans o Clara María de Vega Santos. Maestro, pues, y maestro de maestros que hoy conducen departamentos universitarios de prestigio, participan en grupos de investigación y dirigen trabajos a sus propios discípulos.

Pocas caras de las innumerables que tiene el lenguaje humano y pocos aspectos de los muchos que presenta la lengua española escaparon a su mirada inquieta. Además de la toponimia, ya sacada a colación, a Llorente le 
apasionaba la forma de hablar de la gente, el uso que se hace del español, observar cómo nos expresamos, con qué palabras, con qué construcciones, dónde, cuándo, quiénes... De ahí su reconocido cultivo de la dialectología hispánica, sus escapadas por prácticamente toda la piel de toro para hallar el dato in situ, su mirada atenta a todos los matices en cualquier acto de habla y situación de comunicación. Sus 48 encuestas en Andalucía, sus 104 puntos encuestados en Aragón, Navarra, Rioja, Álava, Burgos, Soria, Guadalajara, Cuenca, Valencia y Castellón, o las 70 localidades visitadas en Zamora, Salamanca y Ávila no son sino una prueba objetiva y cuantificada de su inestimable y nunca suficientemente bien ponderada participación en, por este orden, el Atlas Lingüistico y Etnográfico de Andalucia, el Atlas Lingüistico y Etnográfico de Aragón, Navarra y Rioja o el Atlas Lingüistico de España y Portugal/Atlas Lingüístico de Europa. Sobre tema dialectológico versaron su tesis doctoral ${ }^{3}$ así como varios de los artículos que publicó en la Revista de Filología Española, entre otras contribuciones ${ }^{4}$.

Entre sus aficiones mayores se contaron el estudio del léxico hispánico y el análisis de la distribución geográfica del vocabulario, lo que podríamos denominar la lexicología dialectal ${ }^{5}$. Escudriñó en asuntos delicados de gra-

\footnotetext{
${ }^{3}$ Estudio sobre el habla de La Ribera (comarca salmantina ribereña del Duero), Salamanca, 1947.

${ }^{4}$ Se podrian citar: "El habla de Salamanca y su provincia", en Boletín de la Asociación Europea de Profesores de Español, XIV, 1982, págs. 91-100. "En la Salamanca de las sonoras arcaicas (Las andanzas de un aprendiz de dialectólogo)", en Homenaje a Álvaro Galmés de Fuentes, I, Madrid, 1985, págs. 233-243. Aspectos linguïsticos de la Tierra de Béjar, Béjar, 1986. "Las hablas vivas de Zamora y Salamanca en la actualidad", en Lenguas peninsulares y proyección hispánica, Madrid, 1986, págs. 107-131. "Encuesta en Hinojosa de Duero", en LEA. Homenaje póstumo a J. Fernández Sevilla, Madrid, 1987, págs. 305-313. "Cinco días de encuesta dialectal", en Homenaje al profesor Alonso Zamora Vicente, Madrid, 1990, págs. 197205. "Las hablas aragonesas en las fronteras occidentales (límites con La Rioja, Soria, Guadalajara y Cuenca", en Actas del Congreso de Lingüistas Aragoneses, Zaragoza, 1991, págs. 153167. "Fronteras lingüísticas internas en territorio aragonés", en I Curso de Geografía Lingüistica de Aragón, Zaragoza, 1991, págs. 165-184. "Rasgos fonéticos meridionales en la provincia de Ávila", en Homenaje a Félix Monge. Estudios de lingüística hispánica, Madrid, 1992, págs. 313-323. "El andaluz occidental y el andaluz oriental", en El habla andaluza (Actas del Congreso del Habla Andaluza. Sevilla, 4-7 marzo 1997), Sevilla, 1997, págs. 103-122.

${ }^{5}$ Véanse a este respecto su serie: "Comentario de algunos aspectos del léxico del tomo II del ALEICan", en Actas del Primer Simposio Internacional de lengua española. Las Palmas 1978. "Comentario de algunos aspectos del léxico del tomo I del ALEICan", en Actas del II Simposio Internacional de lengua española. Las Palmas 1981 (recogido y profusamente ampliado en El léxico del tomo I del "Atlas Lingüistico y Etnográfico de las Islas Canarias", Cáceres, 1987). Y "Comentario de algunos aspectos del léxico del tomo III del ALEICan", en Actas del III Simposio Internacional de lengua española. Las Palmas 1984. O estos otros trabajos: "Borro, borra, borrego, burro, borrico", en Miscelánea Filológica dedicada a Mons. A. Griera, II, 1960, págs. 65-77. "Correspondencias entre el léxico salmantino y el léxico de Aragón, Navarra y Rioja", en Serta Philologica F. Lázaro Carreter, I, Madrid, 1983, págs. 329-341. "Un ramillete de voces riberanas. Contribución al inventario del léxico salmantino", en Philologica Hispaniensia in honorem Manuel Alvar, I, Madrid, 1983, págs. 399-417.
} 
mática descriptiva y teórica, que investigó con profusión y en los que detectó detalles y matices nunca entrevistos con anterioridad ${ }^{6}$. Examinó con minucia cuestiones de uso y norma, de estándar y variedades, en las que era ducho, para las que gozaba de especial sentido y sensibilidad, y acerca de las cuales fue consultado - como autoridad fiable e indiscutible- - con harta frecuencia ${ }^{7}$ : se interesó, en resumen, por prácticamente todas las manifestaciones del español hablado y escrito. Y se adentró con sagacidad por los terrenos nunca bien delimitados de la historia de las ideas lingüísticas y/o de la teoría del lenguaje ${ }^{8}$.

"Coincidencias léxicas entre Andalucía y el Valle del Ebro", en Homenaje al Prof. Tomás Buesa Oliver (AFA), Zaragoza, 1985, págs. 347-375. "Las denominaciones de la losa o lancha en las provincias de Zamora, Salamanca y Ávila", en RDTP, XLIII, 1989, 365-377. "Las denominaciones correspondientes a las lexías de la lengua estándar arroyo, torrentera, manantial y terreno pantanoso en Zamora, Salamanca y Ávila (I)", en RFE, LXIX, 1989, págs. 253-275 y (II), en RFE, LXX, 1990, págs. 71-89. "Las denominaciones del "camino de ganado" en las provincias de Zamora, Salamanca y "Ávila", en Estudios románicos. Homenaje al profesor Luis Rubio, II, Murcia, 1990, págs. 797-805. "Las denominaciones del erial en las provincias de Zamora, Salamanca y Ávila", en Estudios humanísticos en homenaje a Luis Cortés Vázquez, II, Salamanca, 1991, págs. 539-552. "Denominaciones del guijarro y del canto rodado en las provincias de Zamora, Salamanca y Ávila", en Estudios filológicos en homenaje a Eugenio de Bustos Tovar, II, Salamanca, 1992, págs. 561-571. "Algunas denominaciones de las formas y de las orientaciones del terreno en Zamora, Salamanca y Ávila", en Scripta Philologica in honorem Juan M. Lope Blanch, II, México, 1992, págs. 145-162. "Las denominaciones del "terrón de tierra" en las provincias de Zamora, Salamanca y Ávila", en Antiqua et Nova Romania. Estudios [...] en honor de José Mondéjar, I, Granada, 1993, págs. 133-147. "Otras denominaciones del guijarro y del canto rodado en las provincias de Zamora, Salamanca y Ávila", en Contribuciones al estudio de la lingüistica hispánica. Homenaje al profesor Ramón Trujillo, págs. 175-184. Ganadería y léxico ganadero en la provincia de Salamanca, Salamanca, 1995.

6 "La conjugación objetiva en las lenguas románicas", Prohemio, III, 1972, págs. 1-27 (en colaboración con José Mondéjar); "La conjugación objetiva en español", RSEL, 4, 1974, págs. 1-60 (en colaboración con José Mondéjar); "Las construcciones de carácter impersonal en español", en Estudios ofrecidos a Emilio Alarcos Llorach, I, Oviedo, 1977, págs. 107-125; "La expresión de la impersonalidad en español", en Actas del Cuarto Congreso Internacional de Hispanistas. Salamanca 1971, Salamanca, 1982, págs. 199-209.

7 Pueden consultarse ahora: "Consideraciones sobre el español actual", en Anuario de Letras, XVIII, 1980, págs. 5-61. El lenguaje estándar español y sus variantes, Salamanca, 1986. "Desviaciones de la norma léxica del español: barbarismos, vulgarismos, semicultismos y otras incorrecciones", en Actas de las II Jornadas de metodología y didáctica de la lengua y la literatura españolas: el léxico, Cáceres, 1991, págs. 71-97. La norma lingüística del español actual y sus transgresiones, Salamanca, 1991. "Innovaciones morfosintácticas, locucionales y léxicas en el español de nuestros días", en Philologica (Homenaje al profesor Ricardo Senabre), Cáceres, 1996, págs. 323-340.

8 Sobradamente citados han sido estos trabajos: Los Principios de Gramática General de Hjelmslev y la Lingüistica (Introducción a la ciencia del lenguaje), Granada, 1953. Morfología y Sintaxis. El problema de la división de la Gramática, Granada, 1955. Gramática general y Lingüistica. Tres ensayos sobre Ciencia del lenguaje, Granada, 1963. Teoria de la lengua e Historia de la Lingüística, Madrid, 1967. "Caracterización de la lingüística grecolatina: ensayo de fijación de criterios para historiar la ciencia del lenguaje", en Miscelánea de estudios dedicados al profesor Antonio Marin Ocete, Granada, 1974, págs. 515-537. 
A todos esos campos y facetas - en escarceos superficiales, incursiones esporádicas, análisis profundos, investigaciones exhaustivas o lucubraciones sesudas- aplicó cualidades raras de encontrar por lo escaso de su distribución entre los humanos y que para él resultaban naturales porque, siéndole tal vez innatas, supo cultivar: buen juicio, ponderación, sentido común, intuición, honradez científica, generosidad intelectual, rigor metodológico... y finísimo sentido del humor. O que había ido adquiriendo en su ansia de satisfacer su también innata curiosidad: dosis y dosis de información, información e información.

Poco dado a camarillas, conciliábulos, compadreos e intrigas; mucho a la charla cordial, a la tertulia abierta y desinteresada, a la amistad, a dar sin llevar la cuenta, sin esperar la vuelta, sin pedir a cambio: generoso. No se le conocen enemigos, cosa bien rara en su profesión (que es la nuestra), y sí legiones de amigos y afectos. Cuando poco antes de cumplir 65 años tocó evitar a toda costa que un profesor de su talla y facultades abandonara aulas y despacho, un grupo de discípulos nos apresuramos a proponerlo para profesor emérito de la Universidad de Salamanca; la noticia se corrió como la pólvora y de todos lados llovieron cartas de adhesión incondicional a la propuesta; nos llegaron firmadas por Alonso Zamora, Antonio Quilis, Rafael Lapesa, Pilar García Mouton, Agustín Vera, Juan A. Frago, Salvador Gutiérrez, Tomás Buesa, M. ${ }^{a}$ Antonia Martín Zorraquino, Félix Monge, José Fco. Val, Fernando Lázaro, Manuel Alvar, Kurt Baldinger, Luis Michelena, José A. Martínez, Valerio Báez, Jacques de Bruyne, Juan M. Lope Blanch, Emilio Alarcos, Bonifacio Rodríguez, Santiago Alcoba, Juan Martínez Marín, etc., etc. En ellas se hablaba de su "silenciosa entrega al trabajo"; su "evidente ejemplaridad"; su carácter de "uno de los hispanistas más prestigiosos de España" o de "sabio de reconocida fama internacional"; su "agudeza de ingenio"; su "autoridad excepcional"; sus "extraordinarias dotes de profesor"; su "bondad y su sentido de la responsabilidad"; su "puntualidad"; su fama, que "rebasa las fronteras de España y abarca todo el mundo de los romanistas que se ocupan de la historia del español"; su "saber de lenguas" o su "rigor científico"; su "amplia labor polifacética que va de lo universalista a lo localista"; su consideración como "uno de los más autorizados filólogos españoles"; etc., etc. Lo escribieron ellos; lo transcribimos y confirmamos nosotros.

Este hombre - sin embargo- no recibió doctorado "honoris causa" por Universidad alguna. $\mathrm{Ni}$ fue objeto de vacuos honores, fastos y pompas; de hecho, los rehuía porque le producían pavor: jamás olvidaré que antes de la comida-homenaje que la Facultad de Filología de la Universidad de Salamanca le brindó con motivo de su jubilación a los 65 años me pidió expresamente, nervioso e intranquilo, que todos los discursos, las encendidas pa- 
labras, los elogios de rigor tuvieran lugar - como proemio- antes de los entremeses y no, - como colofón-- a los postres; en caso contrario, los nervios le impedirían disfrutar de la comida, el acto, los amigos, los colegas, el jubiloso y al tiempo temido, fatídico, día... $\mathrm{Ni}$, aun siendo durante años académico correspondiente, ingresó como miembro de número en la Real Academia Española, lo que a todas luces y a juicio de todos los consultados merecía sobradamente (es posible que incluso él, a pesar de su modestia y humildad, coincidiera con nosotros en este punto); nadie puede dudar de que Llorente habría prestado encantado a la corporación $-\mathrm{y}$ desde ella a la lengua española - innumerables y exquisitos servicios gratuitos y anónimos. Ni... Son éstas cosas que nadie ha podido entender aún y que resultan dificiles [?] de explicar. Pero hizo para dejar excelente recuerdo, humano y profesional, en todos los que lo conocieron: yo por lo menos nunca he oído hablar mal, ni siquiera regular, de él. Y eso es mucho y dice mucho.

Con la Revista de Filologia Española mantuvo a lo largo de toda su vida académica una relación muy especial: en primer lugar, porque en ella publicó su primer trabajo de carácter filológico: una reseña del libro de I. Lahti $L a$ metathèse de l'r dans les idiomes romans (RFE, XXIX, 1945, págs. 330-338).

En segundo lugar, por la predilección que siempre mostró hacia esta publicación periódica para dar a conocer sus investigaciones. Aquí publicó trabajos fundamentales para el conocimiento de los dialectos históricos y actuales del español, trabajos que no han perdido ni un ápice de su vigencia y aún hoy siguen siendo de lectura inexcusable: "Importancia para la historia del español de la aspiración y otros rasgos del salmantino noroccidental" (XLII, 1959, págs. 151-165); "Fonética y fonología andaluzas" (XLV, 1962, págs. 227-240); "Algunas características lingüísticas de La Rioja en el marco de las hablas del Valle del Ebro y de las comarcas vecinas de Castilla y Vasconia" (XLVIII, 1965, págs. 321-350), son buenas muestras de ello.

En tercer lugar, por la asiduidad, constancia y fidelidad de su relación con esta revista. Será difícil encontrar una mayor dedicación y abnegación: entre 1959 y 1990 (¡más de treinta que se dice pronto!) Antonio Llorente pasó en su finca de Sagos veranos y veranos - época, como es sabido, de prolongadas ¿vacaciones? estivales para el profesorado universitario- leyendo, traduciendo, decantando, enjuiciando, seleccionando la enjundia y extrayendo el jugo de los tomos 66 a 94 de las Romanische Forschungen (Frankfurt am Main) y de los volúmenes 67 a 99 de las Zeitschrift für romanische Philologie (Tübingen). Son sus archiconocidas reseñas o análisis de revistas alemanas, lengua en la que era ducho al menos desde el curso 1940-1941 (¡atención a la fecha!), en que estudió en la Universidad de Berlín. ¿Qué decir? Agradecerle el enorme favor que nos hizo a muchos examinando aquellas revistas, dándonos a conocer su contenido, resumiendo 
sus artículos con rigor, acierto y buen juicio, y poniéndonos al alcance de la mano -en español, en román paladino y en extracto- todo lo importante que allí se decía en lenguas difíciles, con estilos abstrusos y por extenso; ahorrando con su quehacer y su entrega tiempo y energías a los demás, tranquilos como estábamos de que su síntesis y valoración de trabajos ajenos eran acertadas, de su ponderación. Labor callada y compleja, de escaso brillo, poco lustre y mucha utilidad; impagable en gratitud y muy probablemente mal —o nunca- pagada en moneda de curso legal.

Bueno, memorioso, entrañable, afable, humilde, sabio, profesor excelente, amante de todos los nombres propios, tolerante, maestro, maestro de maestros, modesto, sencillo, benevolente, generoso, responsable, puntual, filólogo y lingüista de primer orden, riguroso con la ciencia, polifacético, honrado, conversador, comprensivo, irónico, astuto,... Todas esas calificaciones cuadran con las cualidades que adornaban su persona, pero ninguna lo define; todas le encajan, pero ninguna lo encasilla o capta: algo se escapa. Todas, y muchas otras con las que no acierto a dar, ayudan a conocerlo, a caracterizarlo, a hacerse una imagen ciertamente cabal de su persona, pero no permiten verlo con su vieja gabardina beige al hombro, ni disfrutar aprendiendo de su charla amena y erudita, ni atisbar esa sombra de preocupación en su mirada a veces ausente, ni recordar su voz ronca tan característica, ni solidarizarse con su eterna sonrisa socarrona. Si hubiera que elegir sólo tres, yo me quedaría con las que probablemente más perdurarán en mi memoria: sabio, sencillo y bueno; sus otros rasgos caben bajo el amplio manto de éstos.

Este hombre murió en medio del campo (así, creo, lo habría dicho él) o en plena naturaleza, expresión ésta más del gusto de ciertos ecologistas modernos. Y, cosa rara - dadas su sociabilidad, su afabilidad, su habilidad para hacerse acompañar-, en la más absoluta de las soledades. Era una tarde de la canícula de agosto de 1998. Tenía 76 años que él había dedicado a vivir, a aprender, a enseñar, a disfrutar y a hacer disfrutar a los demás.

Confío, lector, en que esto no te haya parecido una necrología y sí una nota jubilosa y alegre - aunque no festiva - de admiración por y gratitud hacia un colaborador de la Revista de Filologia Española, un maestro en muchas artes y de muchos maestros, una persona de bien, un pequeño gran hombre. Tiene, claro está, un mucho de homenaje. E intenta ser, al tiempo, un sencillo y elemental apunte para algún capítulo de esa historia de las ideas lingüísticas españolas en el siglo XX que alguien debería animarse a ir escribiendo.

Valdemierque, primeros de agosto del año 2000 